\title{
TOWARDS CLIMATE CHANGE ADAPTATION OF EXISTING AND NEW DETERIORATING INFRASTRUCTURE
}

\author{
E. Bastidas-Arteaga \\ ${ }^{1}$ Laboratory of Engineering Sciences for Environment, UMR CNRS 7356, La Rochelle University, \\ France.
}

Keywords: Climate change, Adaptation, Infrastructure, Reliability

\begin{abstract}
Infrastructure assets are essential components to the economical development of modern societies. They are designed to ensure target levels of serviceability and safety on the basis on past experiences and current knowledge on design, construction and maintenance practices. However, changes in climate could modify the lifetime performance of infrastructure by increasing or decreasing failure risks. Therefore, a rational and scientific approach is necessary to deal with the adaptation of existing and new deteriorating infrastructure in a comprehensive way. This keynote paper provides an overview of recent works on this area including: (i) assessment of climate change effects, (ii) adaptation to new environmental conditions for future climate change scenarios and (iii) decision-making under a changing climate. Several examples for different kind of deteriorating infrastructure assets are also presented and discussed in this paper.
\end{abstract}




\section{INTRODUCTION}

Infrastructure assets are a key component for the development of modern societies. These assets are designed to provide specific services and are subjected to environmental or operational actions that could affect their serviceability and safety [1]. Among the environmental ones, deterioration processes (corrosion, fatigue, etc.) or extreme events (hurricanes, floods, winds, etc.) are examples of actions that decrease the infrastructure performance gradually or suddenly and could in some cases lead to structural failure.

Design and operation of infrastructure assets is mainly based on the past experiences and knowledge at the design time. Probabilistic approaches are generally directly or indirectly included in the design stage to account for uncertainties related, among others, with environmental actions. Nevertheless, studies on climate change announce variations (increase, decrease, frequency, intensity, etc. [2]) of the patterns of current weather that are not included in the design stage but that could affect the infrastructure performance. Therefore, a rational and scientific approach is necessary to deal with the adaptation of existing and new deterioration infrastructure in a comprehensive way [3].

Adaptation of infrastructure to new environmental conditions is not an easy decision-making task because hard policy choices are needed in the present to deal with consequences in the mid- (20-40 years) or long-term (more than 70 years). The choices should take into account current needs and uncertain and complex future risks under a changing climate. Within this context, this paper provides an overview of recent research works dealing with the topics of: (i) assessment of climate change effects (section 2), (ii) adaptation to climate change (section 3), and (iii) decision-making under a changing climate. Applications to various study cases including power distribution systems, bridges subjected to scour, and corroded reinforced concrete structures are also included in the paper.

\section{EFFECTS OF CLIMATE CHANGE ON INFRASTRUCTURE}

Climate change could affect serviceability and safety of infrastructure assets by three ways: (i) changes (increase/decrease) in the intensity and frequency of extreme events; (ii) changes in the kinetics of deterioration rates; and (iii) a combination of effects on extreme events and progressive deterioration.

The current patterns of extreme events that affect the structural integrity could be affected by climate change. For example, Iman [4] evaluated the effects of climate change on bridges subjected to scour. The development of scour holes, that could induce the bridge failure, is widely influenced by the river flow magnitude. This latter is affected, in turn, by modifications on precipitation patterns that could be affected by climate change. Figure 1 presents some projected changes in seasonal streamflow in various European rivers. It is observed in this figure that future climate conditions could increase or decrease the normalised discharge depending on the location. For some rivers (e.g. Loire, Danube, etc.) there would be future peak values of normalised discharges that will increase bridge scour risks. For other places, the change is not significant or there is a reduction of the normalised discharge that could reduce scour damage. These findings highlight that a comprehensive management of structures subjected to new environmental conditions affected by climate change should account for these local effects. 


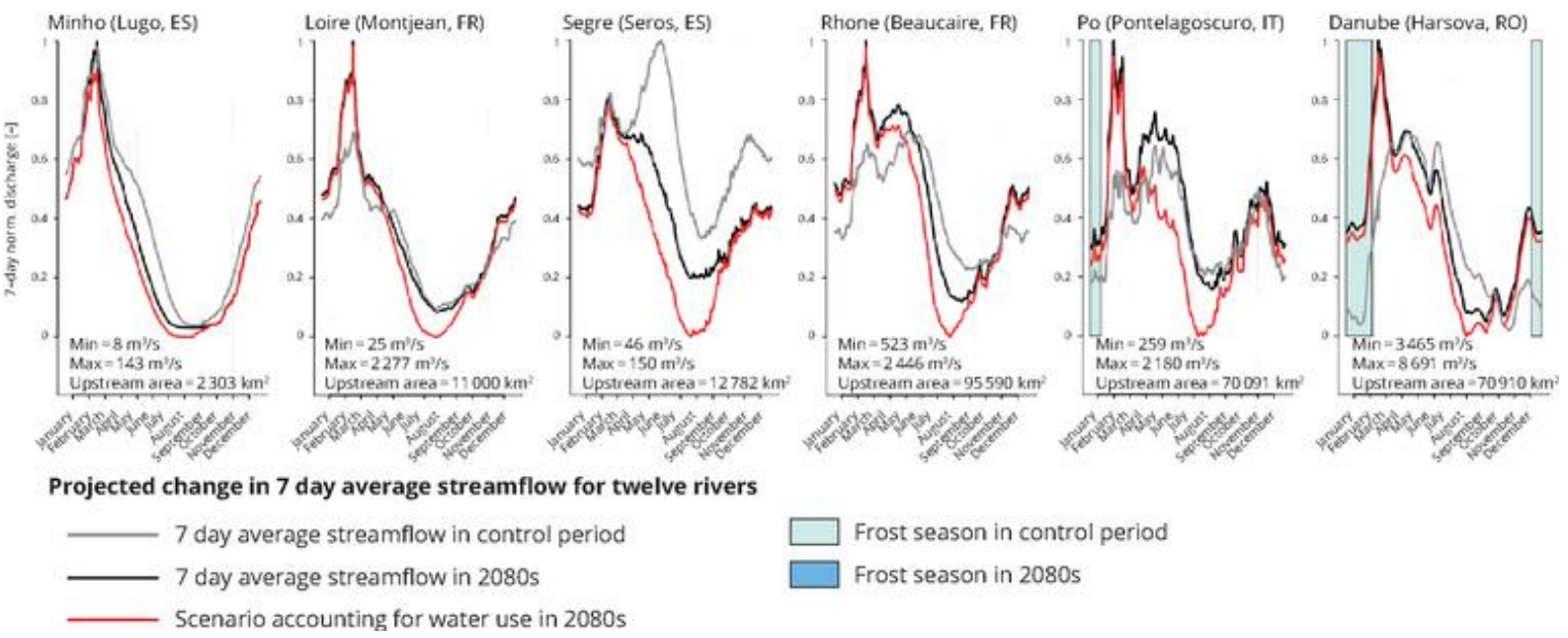

Figure 1: Projected change in seasonal streamflow for rivers in Europe. Source : European Environment Agency (EEA).

Climate change is also affecting the long-term performance of deteriorating infrastructure [511]. For example, Merschman et al [5] studied the effect of variations of temperature and precipitations on the durability of timber poles for power distribution systems subjected to decay. In Figure 2 are given the mean timber decay for timber poles placed in Miami and New York City and subjected to various climate change scenarios (RCP4.5 and RCP8.5). It is observed in this figure that without considering climate change, the local weather of each location provides a different timber decay evolutions where the hotter and rainy weather in Miami increases the decay rate. It is also observed that higher decay rates are expected for the most pessimist scenario (RCP8.5) that announces higher temperature and precipitation by the end of this century. Thus, the lifetime assessment of ageing infrastructures should consider several (optimistic or pessimistic) climate change scenarios to give a wide overview of their potential effects that facilitate the formulation of robust design/maintenance solutions.

(a)

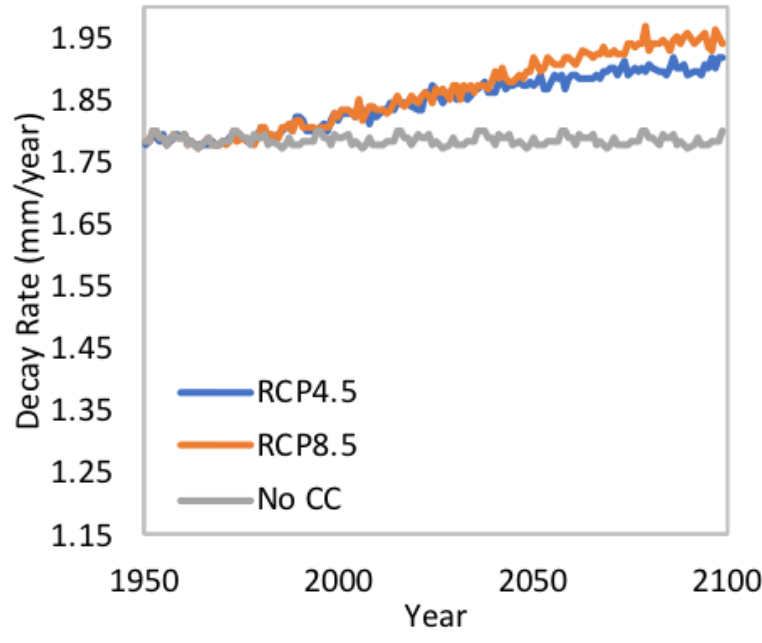

(b)

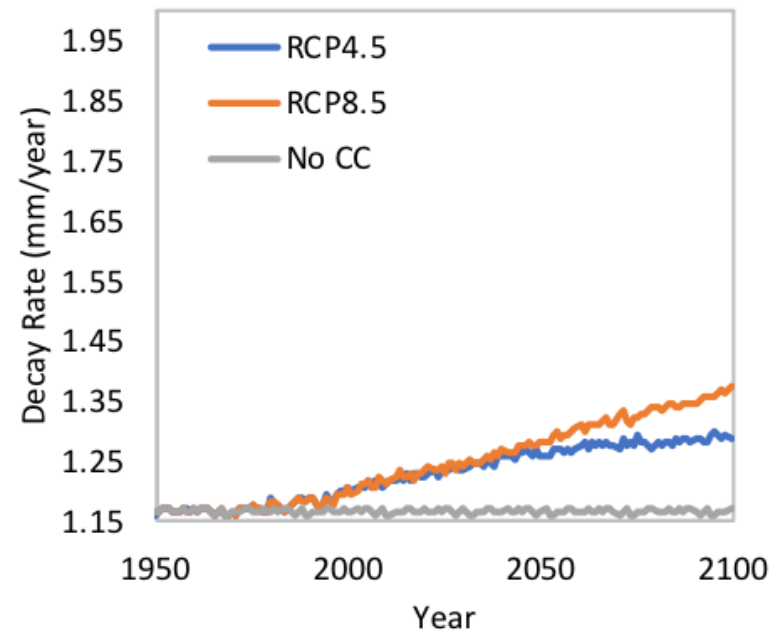

Figure 2: Mean decay rate for (a) Miami and (b) New York City (adapted from [5]).

Merschman et al [5] also considered the combination of progressive deterioration (timber decay) and extreme events (cyclones) on the assessment of climate change of timber poles. Cyclone's intensity and frequency could be affected by climate change; however, nowadays it is still very challenging to assess the extent of these changes for a particular location. Therefore, 
the probabilistic approach proposed by Merschman et al [5] is useful to account for the uncertainties on these future predictions and allows to estimate the probability of failure when considering failure induced by progressive decay and cyclones. In Figure 3 are presented these failure probabilities for timber poles located on New York City by considering two climate change scenarios (RCP4.5 and RCP8.5) and two failure conditions: (i) decay \& cyclones with intensity increase by climate change, and (ii) decay and cyclones without intensity increase by climate change). In all cases, it is observed that climate change increases failure probability with the maximum values for the most pessimistic scenario RCP8.5. It is also noted that the changes of cyclones intensity due to climate change increase significantly the failure probability. Therefore, the consideration of the combined action of extreme events and progressive deterioration was crucial in this example to provide a more realistic assessment of the effects of climate change on the probability of failure of a timber pole.

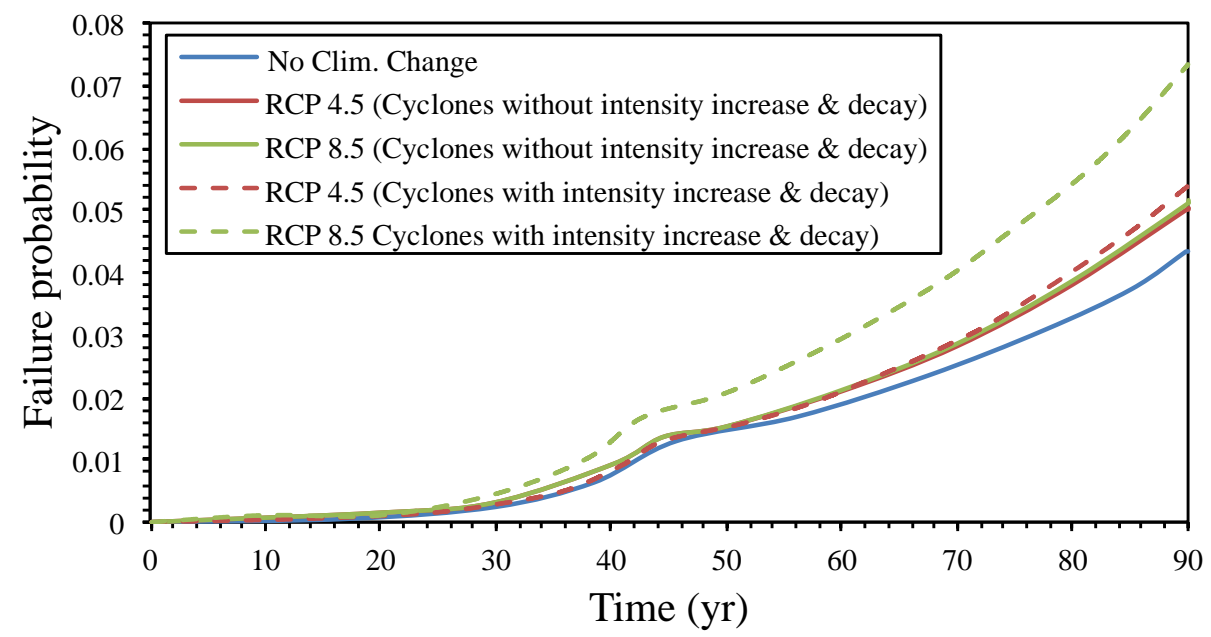

Figure 3: Failure probability for timber poles located in New York City (adapted from [5]).

\section{CLIMATE ADAPTATION}

Adapting existing and new infrastructure assets to future uncertain environmental conditions is a challenging problem of decision-making under uncertainty. Towards this aim, BastidasArteaga and Stewart [3] proposed a framework to estimate the cost-effectiveness of adaptation strategies that combines: (i) models able to estimate the effects of climate change, (ii) stochastic approaches to account for the sources of uncertainty in the problem, (iii) costbenefit analysis to assess the cost-effectiveness of adaptation strategy under a given climate change scenario, (iv) climate change predictions for a particular zone, and (v) the characteristics of the studied infrastructure that depend on the construction year, standards at the construction time, etc.

One of the key points in this framework is the evaluation of costs-effectiveness of adaptation strategies. Cost-benefit analysis in a probabilistic context could be applied to determine the benefit-to-cost ratio and probability of cost-effectiveness for adaptation strategies applied to both new and existing structures [12,13]. The 'benefit' of an adaptation measure is the reduction in damages associated with the adaptation strategy, and the 'cost' is the cost of the adaptation strategy. The benefit-to-cost ratio $\operatorname{BCR}\left(T_{t}\right)$ over the service life period $T_{t}$ is:

$$
\operatorname{BCR}\left(T_{t}\right)=\frac{\mathrm{E}_{\mathrm{d}-\mathrm{BAU}}\left(T_{t}\right) \Delta \mathrm{R}\left(T_{t}\right)}{\mathrm{E}_{\mathrm{a}}\left(T_{t}\right)}, \Delta \mathrm{R}\left(T_{t}\right)=\frac{\mathrm{E}_{\mathrm{d}-\mathrm{BAU}}\left(T_{t}\right)-\mathrm{E}_{\mathrm{d} \text {-adapt }}\left(T_{t}\right)}{\mathrm{E}_{\mathrm{d}-\mathrm{BAU}}\left(T_{t}\right)}
$$


where $\mathrm{E}_{\mathrm{a}}\left(T_{t}\right)$ is the adaptation cost, $\mathrm{E}_{\mathrm{d}-\mathrm{BAU}}\left(T_{t}\right)$ and $\mathrm{E}_{\mathrm{d} \text {-adapt }}\left(T_{t}\right)$ are the cumulative expected damage cost (economic risk) for no adaptation measures (business as usual BAU, or existing practice) and considering adaptation measures, respectively; $\Delta \mathrm{R}\left(T_{t}\right)$ represents the proportional reduction in expected costs due to an adaptation measure. $\mathrm{E}_{\mathrm{a}}\left(T_{t}\right), \mathrm{E}_{\mathrm{d}-\mathrm{BAU}}\left(T_{t}\right), \mathrm{E}_{\mathrm{d}-\mathrm{adapt}}\left(T_{t}\right)$ and $\Delta \mathrm{R}\left(T_{t}\right)$ may be computed from comprehensive models that take into account the effects of climate change $[12,13]$.

An adaptation strategy is cost-effective if the benefit-to-cost ratio is larger than one - i.e., $\operatorname{BCR}\left(T_{t}\right)>1$. In addition, if probabilistic tools are used to propagate uncertainties in the costbenefit analysis, it is possible to estimate the mean value of $\operatorname{BCR}\left(T_{t}\right)>1$, as well as the probability that an adaptation measure be cost-effective, $\operatorname{Pr}\left(\operatorname{BCR}\left(T_{t}\right)\right)>1$. These indicators are very useful to estimate the risk of adaptation investments under several climate change scenarios.

\subsection{Adaptation of existing reinforced concrete infrastructure subjected to chloride- induced corrosion}

Bastidas-Arteaga and Stewart [13] evaluated the cost-effectiveness of adaptation strategies for existing reinforced concrete structures located in Saint-Nazaire (France) under a splash and tidal exposure and designed according to different design standards. Table 1 presents the mean BCR for slabs built in different years under RCP4.5 and RCP8.5 future concentration scenarios. The adaptation strategies consisted on increasing the design concrete cover $\left(c_{a}\right)$ by $\Delta c_{a}=5 \mathrm{~mm}$ or $\Delta c_{a}=10 \mathrm{~mm}$ for repairs carried out after the adaptation time $t_{a}=2020$. The adaptation time is the year after which repairs account for the extra concrete cover $\Delta c_{a}$. The service life period considered is $T_{t}=100$ years.

Table 1: Mean $\operatorname{BCR}\left(T_{t}\right)$ for slabs built in different years and $t_{a}=2020$.

\begin{tabular}{cccccc}
\hline Construction & Design concrete & \multicolumn{2}{c}{ RCP4.5 } & \multicolumn{2}{c}{ RCP8.5 } \\
\cline { 3 - 6 } year & cover $\left(c_{a}\right)$ & $\Delta c_{a}=5 \mathrm{~mm}$ & $\Delta c_{a}=10 \mathrm{~mm}$ & $\Delta c_{a}=5 \mathrm{~mm}$ & $\Delta c_{a}=10 \mathrm{~mm}$ \\
\hline 1970 & $40 \mathrm{~mm}$ & 0.8 & 0.7 & 0.8 & 0.7 \\
1990 & $50 \mathrm{~mm}$ & 3.8 & 3.4 & 3.9 & 3.6 \\
2010 & $55 \mathrm{~mm}$ & 4.6 & 4.3 & 4.7 & 4.5 \\
\hline
\end{tabular}

The values of $\operatorname{BCR}\left(T_{t}\right)$ provided in Table 1 show that this indicator is less than one (1.0) for older structures and greater than one for recent structures, i.e. built in 1990 and 2010. A $\operatorname{BCR}\left(T_{t}\right)$ less than 1.0 implies that the adaptation measure is not cost-effective for old structures, built in 1970. Recent standards recommend larger design concrete covers and are therefore more cost-effective during the service life period. The increase of $\operatorname{BCR}\left(T_{t}\right)$ for recent structures is due, on the one hand, to the larger concrete cover recommended by the standards (Table 1) and/or considered by the adaptation measures. This means that a larger concrete cover is cost-effective for this splash and tidal exposure in Saint-Nazaire. On the other hand, larger $\operatorname{BCR}\left(T_{t}\right)$ values are also related to the increase of climate change effects on chloride ingress rates that justify the implementation of adaptation measures. Table 1 also shows that higher values of the mean $\operatorname{BCR}\left(T_{t}\right)$ are expected for the RCP8.5 scenario that imply more severe changes with respect to the actual climate (Figure 4). The differences between the $\operatorname{BCR}\left(T_{t}\right)$ for both scenarios are slightly larger for recent structures because they will be exposed to larger climate variations that are more pronounced after 2050 for the RCP8.5 scenario (e.g., Figure 4). These climate variations will accelerate chloride ingress, so the costeffectiveness of adaptation strategies will also increase. In all cases, increasing cover by 10 $\mathrm{mm}$ is less cost-effective than a $5 \mathrm{~mm}$ increase in cover. Even if the risk reduction, $\Delta \mathrm{R}\left(T_{t}\right)$, 
should be higher for $\Delta c_{a}=10 \mathrm{~mm}$, the costs associated to this adaptation strategy are larger and thus reduce the mean $\operatorname{BCR}\left(T_{t}\right)$.

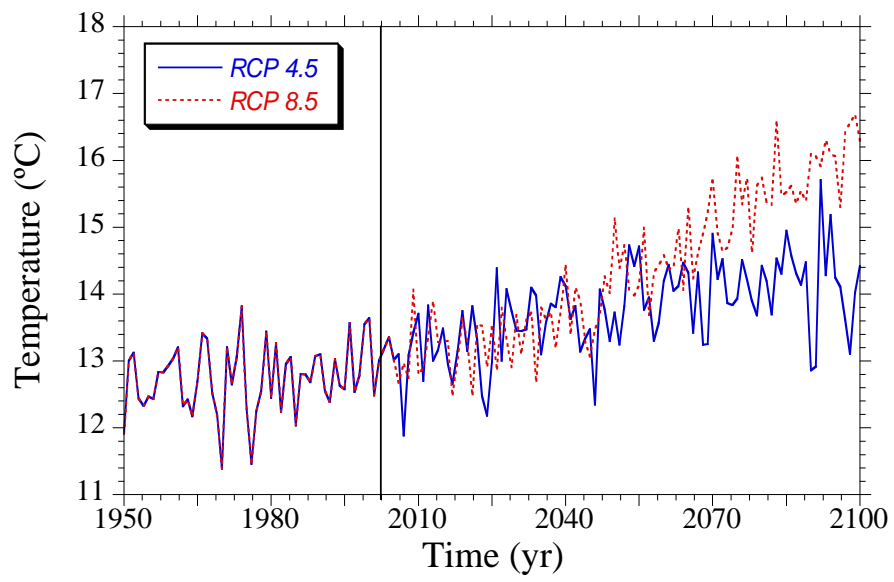

Figure 4: Yearly temperature projections for Saint-Nazaire.

The effect of the time of adaptation on the mean $\operatorname{BCR}\left(T_{t}\right)$ and the probability that $\operatorname{BCR}\left(T_{t}\right)$ exceeds unity $\left(\operatorname{Pr}\left(\operatorname{BCR}\left(T_{t}\right)>1\right)\right)$ for slabs, concrete cover increase $\Delta c_{a}=5 \mathrm{~mm}$ and the RCP4.5 scenario is shown in Table 2. Note that the closer the adaptation year is to the end of the service life period, the lower the mean $\mathrm{BCR}$ and $\operatorname{Pr}\left(\operatorname{BCR}\left(T_{t}\right)>1\right)$ are. Of interest is that $\operatorname{Pr}(\mathrm{BCR}>1)$ only reaches a value of $59 \%$ when the mean BCR exceeds 4 . This illustrates the high variability of damage risks caused by uncertainties of climate change projections, and variability of design parameters and deterioration processes.

Table 2: Mean BCR and $\operatorname{Pr}(\mathrm{BCR}>1)$ (within brackets) for slabs for various $t_{a}$, RCP 4.5 scenario and $\Delta c_{a}=5 \mathrm{~mm}$

\begin{tabular}{ccccc}
\hline Construction & \multicolumn{4}{c}{ Adaptation year $\left(t_{a}\right)$} \\
\cline { 2 - 5 } year & 2020 & 2040 & 2060 & 2080 \\
\hline 1970 & $0.8(6.1 \%)$ & $0.05(0.2 \%)$ & $0(0.0 \%)$ & - \\
1990 & $3.6(43.5 \%)$ & $1.4(10.2 \%)$ & $0.2(0.7 \%)$ & $0(0.0 \%)$ \\
2010 & $4.6(59.0 \%)$ & $3.9(44.7 \%)$ & $1.7(13.1 \%)$ & $0.3(0.9 \%)$ \\
\hline
\end{tabular}

These results could be used by structures' owners and other stakeholders to evaluate the benefits and risks of implementing adaptation strategies at various years. For example, it is observed that the mean $\operatorname{BCR}\left(T_{t}\right)$ and $\operatorname{Pr}\left(\operatorname{BCR}\left(T_{t}\right)>1\right)$ are small for older structures and therefore owners and stakeholders could prioritise investments in adaptation measures for more recent ones. These results could also be used to evaluate the impact of the adaptation year. For example, for structures built in 1990, if the owner or stakeholder decides to postpone the adaptation actions until 2040, the mean $\operatorname{BCR}\left(T_{t}\right)$ is about 1.4 , which is still beneficial. However, the $\operatorname{Pr}\left(\operatorname{BCR}\left(T_{t}\right)>1\right)$ for this adaptation time is less than $11 \%$ indicating that the risks of having no benefits are high.

\subsection{Adaptation of new reinforced concrete infrastructure subjected to chloride-induced corrosion}

This section focuses on the adaptation of new reinforced concrete structures placed in a chloride-contaminated environment under various exposures and climate change scenarios [12]. We particularly focus on structural reinforced concrete components subjected to atmospheric exposure to salt-spray (XS1 exposure according to the European Norm EN 206 [14]). The climatic conditions are defined by an oceanic environment placed at a middle latitude (i.e., Europe) where the yearly mean temperature and relative humidity vary between the intervals $\left[5^{\circ} \mathrm{C} ; 25^{\circ} \mathrm{C}\right]$ and $[60 \% ; 80 \%]$, respectively. The EN 206 [14] durability design requirements 
for a structural lifetime of 100 years and a rebar diameter of $16 \mathrm{~mm}$ are (i) $55 \mathrm{~mm}$ cover, and (ii) $30 \mathrm{MPa}$ concrete compressive strength. The adaption strategy will be to increase the concrete cover by $\Delta c_{a}=5 \mathrm{~mm}$ after the repair time, $t_{\text {rep }}$.

Using the probabilistic model of chloride-induced deterioration given in [15] are obtained the results given in Figure 5 that present the time-dependent probability of severe cracking for various climate change scenarios. Figure 5 clearly shows that the rate of damage risk is highly dependent on climate change effects and environmental exposure. If there is no climate change, the probability of severe cracking increases with time and remains constant for all times of repair. However, if climate change reduces the environmental relative humidity, i.e. $\Delta \mathrm{RH}=-10 \%$ in 100 years, the chloride ingress mechanism slows down, and consequently, the probability of severe cracking decreases. For instance, for a structure with no repairs $\left(t_{\text {rep }}=0\right)$, the probability of damage decreases from $20 \%$ to $8 \%$ after 100 years of service. In this case, climate change has a 'positive effect' on reinforced concrete durability reducing by $60 \%$ the corrosion damage risk. An opposite behaviour is observed when climate change increases the temperature and relative humidity. For the same conditions, the probability of corrosion damage increases from $20 \%$ to $98 \%$.
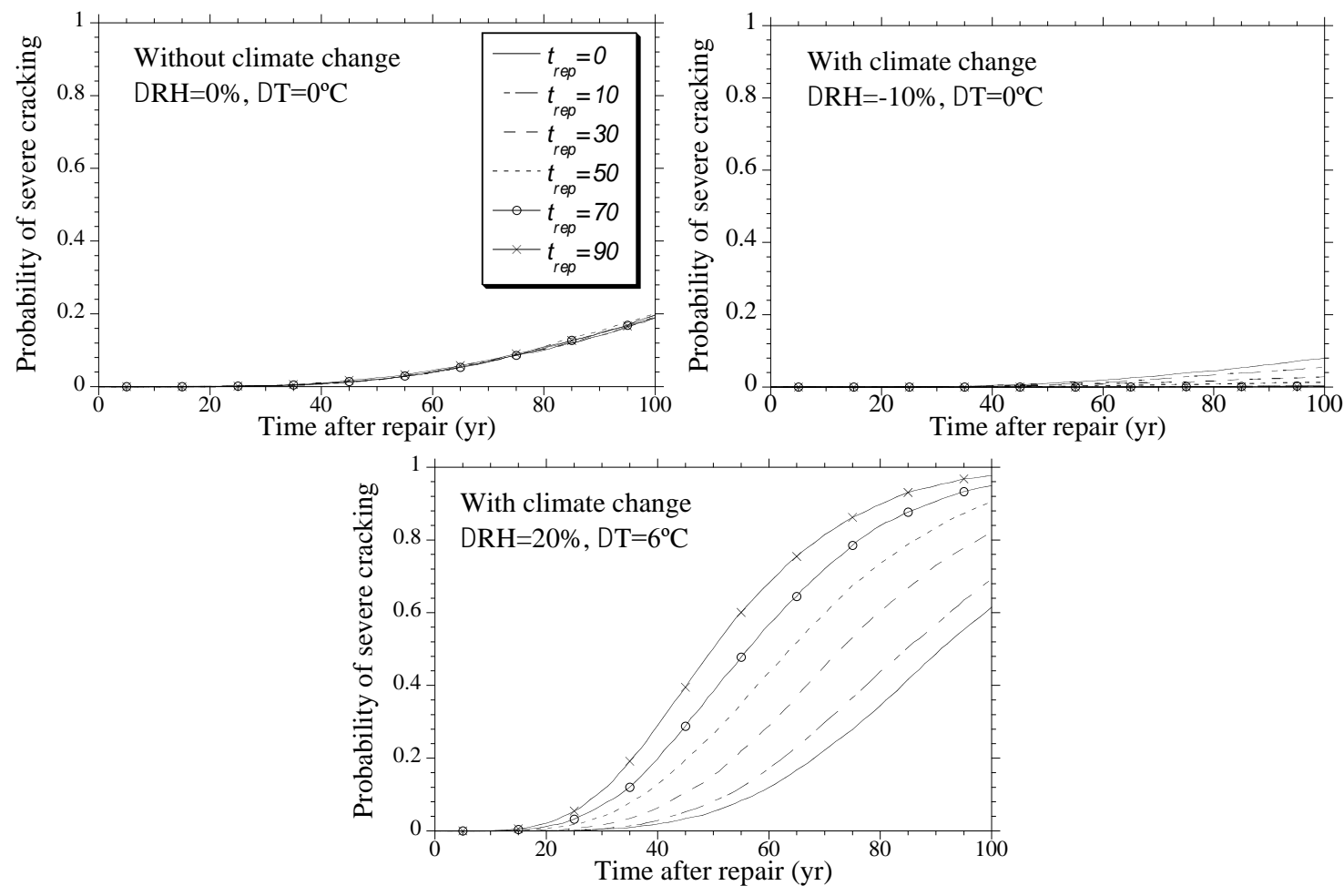

Figure 5: Probability of several cracking after repair for various climate change scenarios.

Table 3 summarises the mean $\mathrm{BCR}$ and $\operatorname{Pr}(\mathrm{BCR}>1)$ for various climate change scenarios and $300 \mathrm{~mm}$ reinforced concrete slabs. The results show that the mean of the BCR is highly dependent on both the exposure and the type of structural component. In some cases the mean BCR is lower than 1 indicating that the adaptation strategy is not cost-effective under given climate change scenarios. Similar behaviour is observed for the $\operatorname{Pr}(\mathrm{BCR}>1)$.

Higher temperature and relative humidity accelerate the deterioration processes by increasing the cost-effectiveness of the implementation of an adaptation measure. In Table 3, the mean BCR is only higher than one when climate change could induce increases of relative humidity equal or higher than $10 \%$ in 100 years. However, even under these scenarios, the $\operatorname{Pr}(B C R>1)$ 
indicates that the risks associated to a bad investment are higher. It is noted that an increase of $5 \mathrm{~mm}$ cover provides higher estimates of $\mathrm{BCR}$ and $\operatorname{Pr}(\mathrm{BCR}>1)$. However, the likelihood that $\mathrm{BCR}>1$ is less than $60 \%$ even for a pessimistic (worst-case) climate change scenario of $\Delta \mathrm{RH}=20 \%$ and $\Delta \mathrm{T}=6^{\circ} \mathrm{C}$.

Table 3: Mean $\mathrm{BCR}$ and $\operatorname{Pr}(\mathrm{BCR}>1)$ (within brackets) for slabs and several climate change scenarios.

\begin{tabular}{ccccccccc}
\hline$\Delta \mathbf{R H}$ & \multicolumn{2}{c}{$\Delta \mathbf{T}=\mathbf{0}^{\circ} \mathbf{C}$} & \multicolumn{2}{c}{$\Delta \mathbf{T}=\mathbf{2}^{\circ} \mathbf{C}$} & \multicolumn{2}{c}{$\Delta \mathbf{T}=\mathbf{4}^{\circ} \mathbf{C}$} & \multicolumn{2}{c}{$\Delta \mathbf{T}=\mathbf{6}^{\circ} \mathbf{C}$} \\
\hline$-10 \%$ & 0.33 & $(8 \%)$ & 0.53 & $(8 \%)$ & 0.57 & $(9 \%)$ & 0.57 & $(9 \%)$ \\
$0 \%$ & 0.68 & $(18 \%)$ & 0.91 & $(20 \%)$ & 0.94 & $(22 \%)$ & 0.95 & $(23 \%)$ \\
$10 \%$ & 1.17 & $(34 \%)$ & 1.27 & $(37 \%)$ & 1.35 & $(38 \%)$ & 1.32 & $(40 \%)$ \\
$20 \%$ & 1.65 & $(50 \%)$ & 1.70 & $(53 \%)$ & 1.72 & $(55 \%)$ & 1.76 & $(59 \%)$ \\
\hline
\end{tabular}

\section{DECISION-MAKING UNDER A CHANGING CLIMATE}

Political, economic and social imperatives could affect the policy-making decision process. The World Resources Report [16] highlights five key elements for effective decision-making: Engagement; Decision relevant information; Institutional design; Tools for planning and policymaking; and Resources [3] that are presented and discussed in the next sections.

\subsection{Engagement}

Early and on-going public and/or private engagement is essential to effective adaptation. The first step to create this engagement will be to identify the different actors involved on the problem. In the case of adaptation of infrastructure and buildings, these actors (or stakeholders) are: governments, academia, owners, users, insurers, communities, designers and constructors. Engaging these actors will be crucial to prioritise needs, provide and recover information, determine acceptable risk levels, and choosing among the possible adaptation solutions. Discussions with these actors will also give them the possibility to express their views to increase the acceptability and applicability of adaptation measures.

Some challenges for improving public/private engagement in civil engineering are related with the type of climate hazard and affected infrastructure or buildings. Concerning the type of hazard, there is a high level of governmental engagement to implement initiatives to reduce vulnerability after an extreme events like floods $[17,18]$. However, the lack of exchanges with the different actors involved in the problem such as the population (i.e., community), led to the implementation of expensive, unpopular and unsuccessful adaptation measures after storm Xynthia in France [19,20]. For progressive climate-related hazards (acceleration of corrosion due to climate change), it is very difficult to create strong engagement with major decisionmakers (government, owners) because climate change effects are expected in the long-term and decision-makers mainly focus on short- or mid-term problems.

Communication and education are also useful tools to increase the awareness of these actors concerning climate change risks. Future evolutions of civil engineering and public administration education programs should also consider that infrastructure and buildings would be subjected to a changing climate that will modify current practices of design, construction and management.

\subsection{Decision-relevant information}

Relevant information is required for different stages of decision-making. This information includes temperature, relative humidity, rainfall, wind speed, sea water level, etc. that is estimated from several global circulation models for different climate change scenarios. For the 
case studies presented in this paper, the information was provided from specialised websites or scientific partners and requires a given level of expertise to define if the databases are well suited for the applications. For example, downscaled data is necessary to obtain representative results in some cases. Under these conditions, it would be difficult for decision-makers to use it directly for assessing climate change effects and cost-effectiveness of adaptation strategies.

In addition to the above-mentioned climate hazards and specific technical information for infrastructure and buildings, other types of data such as demography, economy, social and environmental information are also needed. This information is crucial for vulnerability assessment as well as for understating if the adaptation measures could be locally implemented and accepted.

\subsection{Institutional design}

The implementation of cost-effective adaptation strategies should be administratively supported at different institutional levels (ministries, public or private institutions, regions, states, municipalities). This will require evolutions on current practices to deal in a broad way with the problem. One of the major challenges is to maintain its consistency, completeness and integrity along with the national policies in terms of visions and goals. Towards this aim, the role of centralised agencies is crucial to coordinate these efforts in a comprehensive way.

It is expected that the work of centralised agencies will produce standardised procedures for decision-making under a changing climate sometime in the future. For the moment, some discussions for normalisation have started at national, European and International levels. In Europe CEN (European Committee for Standardisation) and CENELEC (European Committee for Electrotechnical Standardisation) launched the Adaptation to Climate Change Coordination Group (ACC-CG) in 2014 to coordinate standardisation activities in the field. An effort focused in construction, transport and energy sectors has bee initiated and a first guide for addressing climate change adaptation in standards has been produced in 2016 [21].

\subsection{Tools for planning and policymaking}

Advanced models able to simulate the behaviour of infrastructure and buildings under realistic environmental exposure have been employed in the examples mentioned in this paper to assess climate change effects and cost-effectiveness of adaptation strategies. In the current form, these models are useful to provide the information required for adaptation planning and policymaking in the studied applications. However, their use requires a certain level of expertise that is not currently easily accessible for non-academic users. In the future, it is expected that engineers, software and standards will provide the capability to directly integrate climate change issues into infrastructure planning. This will require implementing training programs as well as software development. In the meantime, collaborations between decision-makers, industry and academia will allow useful outputs to be produced to benefit decision-making.

\subsection{Resources}

In the aftermath of extreme events that directly affect communities such as floods, heatwaves and extreme winds, decision-makers urgently provide the necessary financial resources to restore the situation as before as these events. Or preferably, to reinstate infrastructure to a higher (less vulnerable) standard - i.e., to "build back better" [22]. Additional policies may also be adopted to reduce the vulnerability to future extreme events in the mid-term. Nevertheless, increasing the resilience of infrastructure and buildings to face climate change hazards 
would require targeted and sustained long-term funding. Public and/or private engagement motivated by financial incentives would help to promote the culture of long-term planning.

Prioritising spending is a complex task for decision-makers that should optimise their budget to deal with unexpected, short-, mid- and long-term expenditures. To help them in this task, a risk-based decision support containing the elements mentioned in section 3 is useful for the evaluation of adaptation costs. This risk-based decision support is paramount for effective decision-making under a changing climate. Therefore, promoting and funding technical training on this subject among decision-makers will allow them to integrate climate risks into existing decision-making processes.

\section{CONCLUSIONS}

This paper summarised recent contributions to the field of climate adaptation of existing and new deteriorating infrastructure. Climate change could affect the serviceability and safety of infrastructure assets by modifying: (i) the intensity/frequency of extreme events, (ii) the kinetics of the deterioration processes, and (iii) a combination of both. Therefore, a widespread evaluation of the potential effects of climate change is crucial to carry out a realistic lifetime assessment under several climate change scenarios. Once this assessment is completed, adaptation becomes a problem of decision-making under uncertainty. Towards this aim, costbenefit analysis is a very useful tool to evaluate the cost-effectiveness of adaptation strategies. Comprehensive models able to account for the effects of climate change in a probabilistic context are essential to support this cost-benefit analysis. The outcomes of this analysis provide valuable information to estimate the potential benefits and risks of climate adaptation investments. Besides these economic and technical considerations, decision-making requires: engagement of all the stakeholders related to the problem; relevant information for assessing climate change effects and for implementing adaptation measurements; institutional design that facilitate the implementation of adaptation measures; tools for planning and policymaking accessible for non specialists; and substantial/sustained financial resources.

\section{ACKNOWLEDGMENTS}

The work reported in this paper summarises multiple collaborations and discussions with M. Stewart, M. Sánchez-Silva, A. Chateauneuf, F. Schoefs, Y. Li, A. Salman, B. Imam, and J. Matos that are deeply acknowledged by the author.

This paper was carried out in the framework of the Strengthening the Territory's Resilience to Risks of Natural, Climate and Human Origin (SIRMA) project, which is co-financed by the European Regional Development Fund (ERDF) through INTERREG Atlantic Area Programme with application code: EAPA_826/2018. The sole responsibility for the content of this publication lies with the author. It does not necessarily reflect the opinion of the European Union. Neither the INTERREG Europe programme authorities are responsible for any use that may be made of the information contained therein.

\section{REFERENCES}

[1] Clifton JR. Predicting the Service Life of Concrete. MJ 1993;90:611-7. https://doi.org/10.14359/9756.

[2] IPCC. Climate Change 2013: The Physical Science Basis. Contribution of Working Group I to the Fifth Assessment Report of the Intergovernmental Panel on Climate Change. Cambridge, United Kingdom and New York, NY, USA: Cambridge University Press; 2013. 
[3] Bastidas-Arteaga E, Stewart MG. Climate Adaptation Engineering: Risks and Economics for Infrastructure Decision-Making. Butterworth-Heinemann; 2019.

[4] Imam B. Chapter Six - Climate Change Impact for Bridges Subjected to Scour and Corrosion. In: Bastidas-Arteaga E, Stewar MG, editors. Climate Adaptation Engineering, Butterworth-Heinemann; 2019, p. 165-206. https://doi.org/10.1016/B978-0-12-8167823.00006-1.

[5] Merschman E, Salman AM, Bastidas-Arteaga E, Li Y. Assessment of the Effectiveness of Wood Pole Repair Using FRP Considering the Impact of Climate Change on Decay and Hurricane Risk. Advances in Climate Change Research 2020;Accepted.

[6] Bastidas-Arteaga E, Chateauneuf A, Sánchez-Silva M, Bressolette Ph, Schoefs F. Influence of weather and global warming in chloride ingress into concrete: A stochastic approach. Structural Safety 2010;32:238-49. https://doi.org/10.1016/j.strusafe.2010.03.002.

[7] de Larrard T, Bastidas-Arteaga E, Duprat F, Schoefs F. Effects of climate variations and global warming on the durability of RC structures subjected to carbonation. Civil Engineering and Environmental Systems 2014;31:153-64. https://doi.org/10.1080/10286608.2014.913033.

[8] Bastidas-Arteaga E. Reliability of Reinforced Concrete Structures Subjected to Corrosion-Fatigue and Climate Change. International Journal of Concrete Structures and Materials 2018;12. https://doi.org/10.1186/s40069-018-0235-x.

[9] Ryan PC, Stewart MG, Spencer N, Li Y. Reliability assessment of power pole infrastructure incorporating deterioration and network maintenance. Reliability Engineering \& System Safety 2014;132:261-73. https://doi.org/10.1016/j.ress.2014.07.019.

[10] Talukdar S, Banthia N. Carbonation in Concrete Infrastructure in the Context of Global Climate Change: Model Refinement and Representative Concentration Pathway Scenario Evaluation. Journal of Materials in Civil Engineering 2016;28:04015178. https://doi.org/10.1061/(ASCE)MT.1943-5533.0001438.

[11] Salman AM. Optimization of Condition-Based Maintenance of Wood Utility Pole Network Subjected to Hurricane Hazard and Climate Change. Frontiers in Built Environment 2020;6:18.

[12] Bastidas-Arteaga E, Stewart MG. Damage risks and economic assessment of climate adaptation strategies for design of new concrete structures subject to chloride-induced corrosion. Structural Safety 2015;52:40-53. https://doi.org/10.1016/j.strusafe.2014.10.005.

[13] Bastidas-Arteaga E, Stewart MG. Economic assessment of climate adaptation strategies for existing reinforced concrete structures subjected to chloride-induced corrosion. Structure and Infrastructure Engineering 2016;12:432-49. https://doi.org/10.1080/15732479.2015.1020499.

[14] EN-206. Concrete - Part 1: Specification, performance, production and conformity. Comité Européen de Normalisation; 2000.

[15] Bastidas-Arteaga E, Chateauneuf A, Sánchez-Silva M, Bressolette Ph, Schoefs F. A comprehensive probabilistic model of chloride ingress in unsaturated concrete. Engineering Structures 2011;33:720-30. https://doi.org/10.1016/j.engstruct.2010.11.008.

[16] World Resources Report. Decision Making under a Changing Climate: Adaptation Challenges and Choices. United Nations; 2011.

[17] Creach A, Bastidas-Arteaga E, Pardo S, Mercier D. Vulnerability and costs of adaptation strategies for housing subjected to flood risks: Application to La Guérinière France. Marine Policy 2020;117:103438. https://doi.org/10.1016/j.marpol.2019.02.010.

[18] Creach A, Bastidas-Arteaga E, Pardo S, Mercier D. Chapter Eight - Adaptation of Residential Buildings to Coastal Floods: Strategies, Costs and Efficiency. In: Bastidas- 
Arteaga E, Stewar MG, editors. Climate Adaptation Engineering, ButterworthHeinemann; 2019, p. 245-70. https://doi.org/10.1016/B978-0-12-816782-3.00008-5.

[19] Mercier D, Chadenas C. La tempête Xynthia et la cartographie des «zones noires » sur le littoral français : analyse critique à partir de l'exemple de La Faute-sur-Mer (Vendée). Norois 2012; ${ }^{\circ}$ 222:45-60.

[20] Pitié C, Puech P. Expertise complémentaire des zones de solidarité délimitées en Vendée suite à la tempête Xynthia survenue dans la nuit du 27 au 28 février 2010. CGeDD / MEEDDM; 2010.

[21] CEN-CENELEC. Guide for addressing climate change adaptation in standards. Committee for Standardization, European Committee for Electrotechnical Standardization.; 2016.

[22] NCCARF. Climate proofing Australia's infrastructure. Policy Brief 7, National Climate Change Adaptation Research Facility, Griffith University, Australia; 2017. 